\title{
List of documents issued by the Conference of European Statisticians
}

July 1983-June 1984

Copies of the documents listed can be obtained (subject to availability) from the Statistical Division of the ECE, Palais des Nations, CH-1211 Geneva 10. Documents are generally available in English, French and Russian.

- The organization of statistical services - centralization and decentralization (CES/504)

- Organization of electronic data processing in official statistics (CES/504/Add.1)

- Some aspects of centralization and decentralization in electronic data processing in the system of the USSR Central Statistical Board (CES/504/Add.2)

- Organization of statistical data processing - centralization and decentralization (CES/504/Add.3)

- Organization of electronic data processing in national statistical offices centralization versus decentralization: The French Agricultural Statistics System (CES/504/Add.4)

- Centralized versus decentralized data processing in statistical organizations (CES/504/Add.5)

- Development of training programmes for personnel of statistics offices in the light of new technological development (CES/505)

- Improvement of professional qualification in the field of statistics in the Socialist Republic of Romania (CES/505/Add.1)

- Training programmes for statistical personnel in view of technological changes: the Turkish case (CES/505/Add.2)

- Development of training programmes for personnel of statistical offices in the light of new technological developments (CES/504/Add.3)

- New technology and Yugoslav statistics (CES/505\%Add.4)

- Statistical activities under the programme of the subsidiary bodies of the Economic Commission for Europe in 1984/1985 (CES/506)

- Statistical activities of international organizations (CES/507)

- Statistical work of the Commission of the European Communities (CES/50)/Add.1)

- Statistical activities of the Organisation for Economic Co-operation and Development (CES/50)/Add.2)

- Information on multilateral co-operation among member countries of the 
Council for Mutual Economic Assistance in the field of statistical methodology in 1983-1984 (CES/507/Add.3)

- The activities of the Council of Europe in the statistical field (CES/507/Add.4)

- Co-operation of the ECE secretariat with other international organizations (CES/50)/Add.5)

- Statistical co-operation between the Nordic countries (CES/507/Add.6)

- Statistical report on activities of the ECE/UNDP statistical computing project in 1983 (CES/508)

- Progress report on the activity of the Computing Research Centre, Bratislava, for 1983 (CES/509)

- Training activity of SZAMALK in 1983 (CES/510)

- Topics for substantive discussion at the thirty-third and later plenary sessions (CES/511)

- Possible areas of international comparisons within the programme of work of the Conference of European Statisticians (CES/512)

- International comparisons (CES/513)

- Summary of the results of the European comparisons programme (CES/514)

- Statistics of water use and quality (CES/515)

- Statistics of air quality (CES/516)

- Statistics of solid wastes (CES/517)

- General methodological problems in environment statistics (CES/518)

- Price observations carried out by ECE member countries in other countries (CES/519)

- Programme of work for 1984/85-1988/89 (CES/520)

- Continuation of the Statistical Computing Project after 1984 (CES/521)

- Direction of work of the CES in the field of the use of computers for statistical purposes (CES/522)

- Review of the European comparison programme (CES/523)

- Towards a system of indicators characterizing the economic and social development of a country (CES/524)

- Grouping of meetings in the field of environment statistics (CES/525)

- Matters arising from the thirty-ninth session of the Economic Commission for Europe (CES/526)

- Report of the thirty-second session of the Conference of European Statisticians (ECE/CES/24)

- Usage of sampling methods in different phases of the censuses of population and/or housing conducted in ECE countries in or around 1980 (CES/SEM.17/2) - Plans for future work on the preparation of recommendations for the 1990 round of population and housing censuses in the ECE region (CES/SEM.17/3) - Report of the Seminar on the evaluation of census results and methodologies held in Rome, 7-11 May 1984 (CES/SEM.17/4)

- Problems on the integration of the population census and the system for civil registration (CES/SEM.17/R.1)

- Automatic processing of the results of the 1980 population and household census in Czechoslovakia (CES/SEM.17/R.2)

- Problems experienced during the preliminary, main and follow-up surveys - 
problems of the 1983 population census in the Federal Republic of Germany (CES/SEM.17/R.3)

- The 1980 population and housing census of Hungary - evaluation of the census results and methods (CES/SEM.17/R.4)

- Preparatory work, data collection and other operations in the 1981 population census of Italy (CES/SEM.17/R.5)

- Problems encountered in the pre-enumeration phases of the Norwegian population and housing census 1980 (CES/SEM.17/R.6)

- The influence of preparatory works on the completeness of census (CES/SEM.17/R.7)

- Automated coding of occupation and socio-economic classification in the 1980 census of population (CES/SEM.17/R.8)

- Diagrams and thematic mapping in the Swedish population and housing census of 1980 (CES/SEM.17/R.9)

- Preparatory work in the field for the 1977 population and housing census in Romania (CES/SEM.17/R.10)

- The organization and conducting of population censuses in the Soviet Union (CES/SEM.17/R.11)

- Problems encountered in different phases of the census - the case of the United Kingdom (CES/SEM.17/R.12)

- The experience of the people's Republic of Bulgaria in a sample application at the different stages of the population census (CES/SEM.17/R.13)

- The use of sampling in the 1981 census of Canada (CES/SEM.17/R.14)

- National experience regarding the use of sample surveys during the various phases of census-taking (CES/SEM.17/R.15)

- Use of the sampling method in the 1981 census of population in Italy (CES/SEM.17/R.16)

- Norwegian experiences in the use of sampling in different phases of the census (CES/SEM.17/R.17)

- Polish experiences in the use of sampling in population censuses in 1950-1983

(CES/SEM.17/R.18)

- Sampling in the 1981 census in the United Kingdom (CES/SEM.17/R.19)

- Two instances of sample checking of the coding and collection of data from the French census of 1982 (CES/SEM.17/R.20)

- Measuring the quality of data in the 1981 census of population and housing of Canada (CES/SEM.17/R.21)

- Quality of census data in Italy (CES/SEM.17/R.22)

- The 1980 Federal population census: ways of filling in gaps and correcting individual forms (CES/SEM.17/R.23)

- Checks of the coverage of the 1981 censuses in the United Kingdom (CES/SEM.17/R.24)

- Statistics for small areas (CES/SEM.17/R.25)

- Data processing and dissemination at the microarea level in the Italian census (CES/SEM.17/R.26)

- Census small area statistics - the case of the United Kingdom (CES/SEM.17/R.27 and Ad.1) 
- Preparation and holding of the population census in Czechoslovakia and processing of results (CES/SEM.17/R.28)

- Coverage and content errors in the 1980 U.S. Decennial methodology (CES/SEM.17/R.29)

- Statistical information systems design (CES/SEM.16/2)

- The use of mini- and microcomputers as integrated parts of the statistical data processing system (CES/SEM.16/3)

- User-friendliness of interface (CES/SEM.16/4)

- Report of the ISIS '84 Seminar held in Geneva, 16-19 April 1984 (CES/SEM.16/5)

- Conceptual planning of the development of the statistical information system (CES/SEM.16/R.1)

- The creation of the Federal data bank as a tool for high-level processing of statistical information (CES/SEM.16/R.2)

- Computer-based data transfer in the statistical information system (CES/SEM.16/R.3)

- Standardization of statistical information systems (CES/SEM.16/R.4)

- Statistical information systems design with Niam (CES/SEM.16/R.5)

- The employment statistics system (CES/SEM.16/R.6)

- The co-operation of the system of State statistics with other systems of socio-economic information in the implementation of the economic reform in Poland (CES/SEM 16/R.7)

- The software architecture of the statistical information system of the German Democratic Republic (CES/SEM.16/R.8)

- Some problems in the processing and analysis of multi-response questionnaires (CES/SEM.16/R.9)

- The acquisition, support and use of small computers in the United Kingdom statistical service (CES/SEM.16.R.10)

- Some aspects of minicomputers use in the statistical information system (CES/SEM.16/R.11)

- The impact of microcomputers on the statistical environment (CES/SEM.16/R.12)

- Comments on decentralization and some experiences in the use of mini- and microcomputers within statistical processing systems (CES/SEM.16/R.13)

- GPS - A user-friendly system for the graphical presentation of statistical data (CES/SEM.16/R.14)

- The utilization of terminals for formulating requirements of outputs in the statistical pràctice of the FSO (CES/SEM.16/R.15)

- Personal computers and graphical applications in Statistics: plans and considerations (CES/SEM.16/R.16)

- The need for, and the use of environmental indicators (CES/AC.58/2)

- Environmental concerns with a view to developing a system of environmental indicators (CES/AC.58/3)

- Measures of ecosystem distress (CES/AC.58/4)

- Experience gained with a river quality classification in England and Wales (CES/AC.58/5) 
- Report of the meeting on environmental indicators held in Geneva, 19-22 March 1984 (CES/AC.5876)

- The harmonization and revision of international economic classifications (CES/AC.59/2)

- The revision of the Standard International Trade Classification (SITC) (CES/AC.59/3)

- The integrated system of classification of activities and products (CES/AC.59/4)

- The revision of the International Standard Industrial Classification of All Economic Activities (CES/AC.59/5)

- The combined Trade/Production Goods Classification (CES/AC.59/6)

- Report of the meeting on economic classifications held in Geneva, 20-24 February 1984 (CES/AC.59/7)

- Use of population and housing censuses as single-source multi-subject data bases; preliminary results of an inquiry in selected countries (CES/WP.34/36)

- The use of population censuses as multi-subject data bases (CES/WP.34/37)

- The use of population censuses as multi-subject data bases in the FRG (CES/WP.34/38)

- Experiences in socio-economic classifications in censuses and other data sources in Cyprus (CES/WP.34/39 and Add.1)

- On the usage of internationally recommended socio-economic classifications and their utility (CES/WP.34/40)

- Finnish experiences with socio-economic classifications in censuses (CES/WP.34/41 and Addendum)

- Hungarian experiences in implementing recommended socio-economic classifications in censuses and other data sources (CES/WP.34/42)

- Experiences and problems in the use of socio-economic classifications in censuses data and in other statistics CES/WP.34/43)

- Experiences in implementing socio-economic classification in the Netherlands (CES/WP.34/44)

- The Norwegian socio-economic classifications (CES/WP.34/45)

-- Socio-economic groups in the 1981 censuses of Portugal (CES/WP.34/46 and

Addendum)

- Experience of the Swedish socio-economic classification (CES/WP.34/47 and Addendum)

- Socio-economic groups and their utilization in population censuses in Switzerland (CES/WP.34/48)

- UK expertise in implementing the recommended socio-economic classifications in the 1981 population census (CES/WP.34/49)

- Social indicators (CES/WP.34/50)

- Information from the secretariat of the Council for Mutual Economic Assistance on the main forms of multilateral co-operation between the countries members of CMEA for the development and improvement of the system of indicators for social statistics (CES/WP.34/50/Add.1)

- Review of developments in the work of the Statistical Office of the European Communities on social indicators (CES/WP.34/50/Add.2) 
- The OECD social indicator development programme (CES/WP.34/50/Add.3)

- Progress report on international work on the framework for integration of social, demographic and related statistics and on related statistical activities (CES/WP.34/51 and Addendum)

- The integration of economic and social statistics - general issues (CES/WP.34/52 and Addendum)

- Turkish experiences with the use of socio-economic classifications (CES/WP.34/53)

- The new nomenclature for determining the structure of households (CES/WP.34/54)

- The new nomenclature of occupations and socio-occupational categories (CES/WP.34/55)

- Report of the eight session of the Working Party on the Framework for the Integration of Social and Demographic Statiștics (CES/WP.34/56)

- Guideline for quality presentations that are prepared for users of statistics (CES/AC.48/32)

- Possible future work (CES/AC.48/33)

- Non-response in panel surveys - some Norwegian experiences (CES/AC.48/34)

- Respondent burden and non-response - an empirical study (CES/AC.48/35)

- Estimation for small domains. Two studies using combined data from censuses, surveys and registers (CES/AC.48/36)

- Non-response - what it is and what we do about it (CES/AC.48/37)

- Estimating after-tax income using survey and administrative data (CES/AC.48/38)

- Linkage of data from different sources (CES/AC.48/39)

- Problems of linkage of data from different sources with special respect to the respondent burden (CES/AC.48/40)

- The problem of non-response in a labour force inquiry (CES/AC.48/41)

- Reducing the non-response bias by asking the basic question (CES/AC.48/42)

- A system of co-ordinated sampling to spread response burden of enterprises (CES/AC.48/43)

- An empirical comparison of two modes of data collection: the same survey by telephone and in person (CES/AC.48/44)

- The contribution of the fusion of files to the quality of statistics - the example of annual business surveys and profits tax declarations (CES/AC.48/45)

- The business statistics survey in France and consistency between sources (CES/AC.48/46/Rev.1)

- The non-response problem - The example of the health study (CES/AC.48/47)

- Surveys and registers - analysis and mutual complementations (CES/AC.48/48)

- Methodology of panel surveys (CES/AC.48/49)

- Treatment and evaluation of non-response in some Spanish surveys (CES/AC.48/50)

- The system of unified evaluation of data collection from various sources in Turkey (CES/AC.48/51)

- Report of the meeting on statistical methodology held in Geneva, 21-24 November 1984 (CES/AC.48/52) 